\title{
Does conventional specimen radiography after neoadjuvant chemotherapy of breast cancer help to reduce the rate of second surgeries?
}

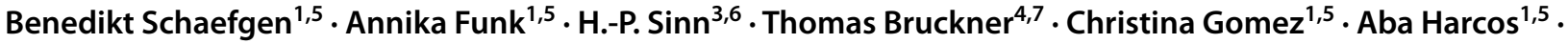 \\ Anne Stieber ${ }^{2,8}$. Annabelle Haller ${ }^{1,5}$. Juliane Nees ${ }^{1,5} \cdot$ Riku Togawa $^{1,5}$. André Pfob ${ }^{1,5}$. André Hennigs ${ }^{1,5}$. \\ Johanna Hederer $^{1,5} \cdot$ Fabian Riedel $^{1,5} \cdot$ Sarah Fastner $^{1,5}$. Christof Sohn ${ }^{1,5} \cdot$ Jörg Heil ${ }^{1,5} \cdot$ Michael Golatta $^{1,5}$ (D)
}

Received: 21 July 2021 / Accepted: 4 November 2021 / Published online: 8 December 2021

(c) The Author(s) 2021

\begin{abstract}
Purpose This is the first study to systematically evaluate the diagnostic accuracy of intraoperative specimen radiography on margin level and its potential to reduce second surgeries in patients treated with neoadjuvant chemotherapy.

Methods This retrospective study included 174 cases receiving breast conserving surgery (BCS) after neoadjuvant chemotherapy (NACT) of primary breast cancer. Conventional specimen radiography (CSR) was performed to assess potential margin infiltration and recommend an intraoperative re-excision of any radiologically positive margin. The histological workup of the specimen served as gold standard for the evaluation of the accuracy of CSR and the potential reduction of second surgeries by CSR-guided re-excisions.

Results 1044 margins were assessed. Of 47 (4.5\%) histopathological positive margins, CSR identified 9 correctly (true positive). 38 infiltrated margins were missed (false negative). This resulted in a sensitivity of $19.2 \%$, a specificity of $89.2 \%$, a positive predictive value (PPV) of $7.7 \%$, and a negative predictive value (NPV) of $95.9 \%$. The rate of secondary procedures was reduced from 23 to 16 with a number needed to treat (NNT) of CSR-guided intraoperative re-excisions of 25.

In the subgroup of patients with cCR, the prevalence of positive margins was 10/510 (2.0\%), PPV was 1.9\%, and the NNT was 85 .

Conclusion Positive margins after NACT are rare and CSR has only a low sensitivity to detect them. Thus, the rate of secondary surgeries cannot be significantly reduced by recommending targeted re-excisions, especially in cases with cCR. In summary, CSR after NACT is inadequate for intraoperative margin assessment but remains useful to document removal of the biopsy site clip.
\end{abstract}

Keywords Breast cancer $\cdot$ Breast conserving therapy $\cdot$ Surgical margins $\cdot$ Intraoperative re-excision $\cdot$ Specimen radiography $\cdot$ Neoadjuvant chemotherapy

$\begin{array}{ll}\text { Abbreviations } \\ \text { BCS: } & \text { Breast conserving surgery } \\ \text { cCR: } & \text { Clinical complete response } \\ \text { CI: } & \text { Confidence interval } \\ \text { CSR: } & \text { Conventional Specimen Radiography } \\ \text { NACT: } & \text { Neoadjuvant chemotherapy } \\ \text { NNT: } & \text { Number needed to treat } \\ \text { NPV: } & \text { Negative predictive value } \\ \text { pCR: } & \text { Pathological complete response }\end{array}$

Michael Golatta

michael.golatta@med.uni-heidelberg.de

Extended author information available on the last page of the article
PMR: $\quad$ Positive margin rate

PPV: $\quad$ Positive predictive value

\section{Introduction}

In the past decades, breast conserving surgery (BCS) has become the standard surgical approach for early breast cancer, and leads to equal [1,2] or superior [3, 4] overall survival compared to mastectomy. Neoadjuvant chemotherapy (NACT) is the standard approach for high-risk cancer patients and can lead to a significant reduction of tumor mass. Often this allows a further reduction of the extent of breast surgeries, which contributes to an improvement of 
the esthetic outcome and patient satisfaction [5-7] as well as a higher quality of life [8,9] and a reduced risk of postoperative complications. The surgeon should try to remove as little healthy tissue as possible while avoiding tumor-infiltrated (positive) resection margins, which are a risk factor for local recurrence [10]. Conventional specimen radiography (CSR) using mammography in two orthogonal orientations is used to assess the margin status and recommend intraoperative re-excision if necessary. Ideally, this leads to tumor free resection margins and can help to avoid a secondary re-excision. The proportion of patients who actually benefit from CSR depends on the prevalence of initially positive margins. Thanks to more frequent administration and more effective systemic treatment options, an increasing number of patients achieve a pathological complete response (pCR) after NACT [14]. Thus, the prevalence of initially positive margins is expected to be lower in patients after NACT and the use of CSR seems questionable in the postneoadjuvant setting [15].

\section{Materials and methods}

This study was approved by the ethics committee of the University's Medical Faculty under file number S-468/2016.

\section{Patient population}

Patients treated at the Breast Unit with BCS after NACT of invasive breast cancer between January 2014 and December 2015 were included consecutively in the analysis. Cases that did not receive CSR $(n=57)$, mostly for reasons of palpability, or did not receive NACT $(n=471)$ were excluded from further analysis. For subgroup analysis, patients' response to NACT was classified as clinical complete response (cCR; defined as the absence of evidence of residual tumor in clinical examination, ultrasound, and mammography after NACT) and non-cCR (Fig. 1).

\section{Conventional specimen radiography and surgical procedure}

Preoperative wire-localization using ultrasound or stereotactic guidance was performed and controlled by mammography.

The specimen orientation was marked by sutures of different lengths according to institutional standard operating procedures. CSR was performed in the breast unit using Mammomat Inspiration (Siemens AG, Erlangen, Germany) with $1.4 \times$ direct magnification in two orthogonal views without compression. One of six physicians with more than ten years of experience in diagnostic mammography and CSR evaluated the position of the target lesion and its relation to the resection margins. Clinical history and previous images were available to the radiologist. If any of the margins appeared to be infiltrated, the radiologist advised the surgeon to perform an intraoperative re-excision of the same orientation.

The pathologic workup of the specimen and the re-excisions was the gold standard for the evaluation of the diagnostic accuracy of CSR. According to the national guideline at the time of data collection (2014-2015), a positive margin was defined as $<1 \mathrm{~mm}$ in invasive carcinoma and $<2 \mathrm{~mm}$ in ductal carcinoma in situ (DCIS) [16], defining the indication

Fig. 1 Flow diagram of patient population

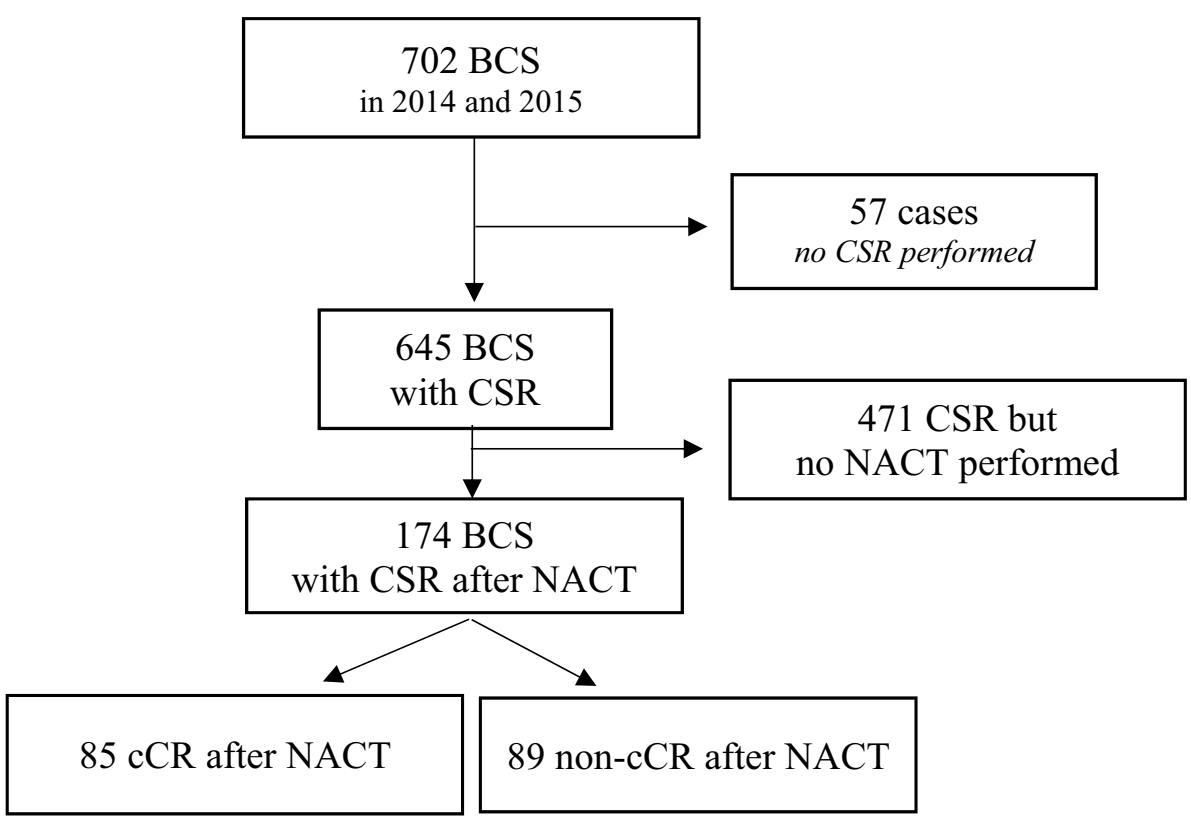


for re-excision. According to the guideline of 2017, a clear margin was defined as "no ink on tumor" [17] (Fig. 2).

\section{Statistical analysis}

Descriptive analyses were performed using IBM SPSS Statistics Version 26, (Armong, NY, USA). Sensitivity and specificity of CSR was calculated along with $95 \%$ confidence intervals using SAS 9.4 WIN (Cary, NC, USA). One sided Chi-square-test was used to assess the level of significance of the differences in sensitivity and specificity among the subgroups. P-values are not adjusted for multiplicity and must be interpreted descriptively.

The primary endpoint was the NNT to avoid a second surgery by CSR-guided intraoperative resections.

\section{Results}

174 patients received BCS after NACT and were included in this analysis (Table 1). For each primary resection specimen, six margins were assessed (1044 in total).

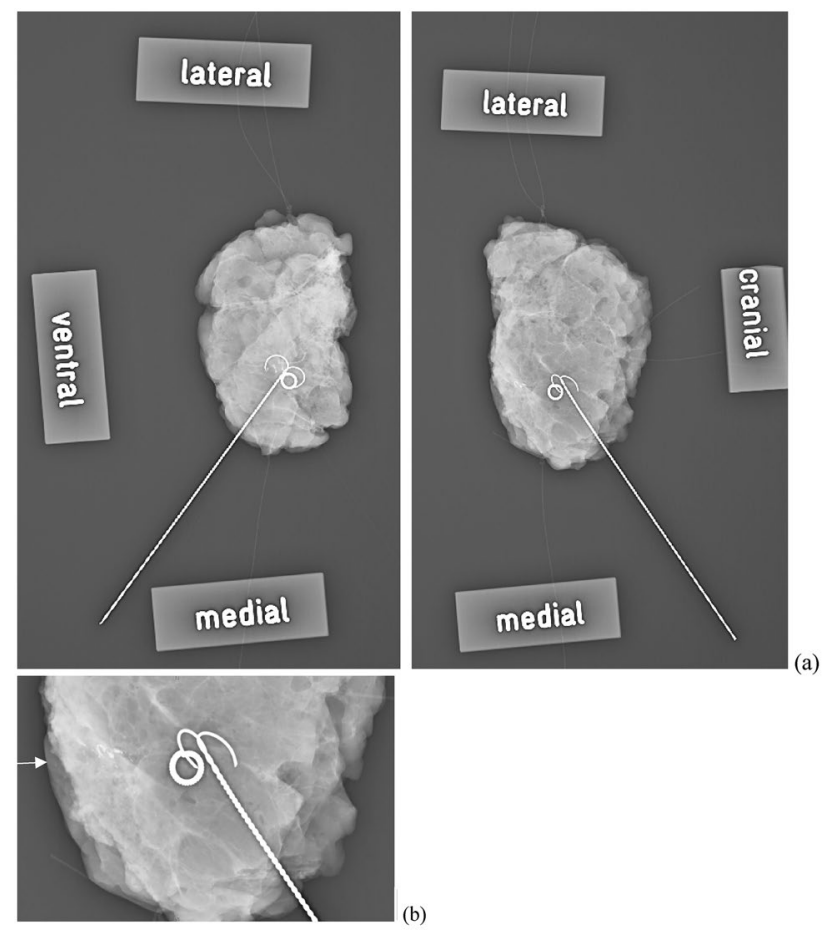

Fig. 2 Example of a conventional two-view specimen radiograph of a cCR patient. Marking wire and clipmarker are visible in the former tumor bed (a). In the twofold magnification of CSR, residual microcalcifications with insufficient margin width in the dorsal direction are visible, so re-excision was recommended in this direction (b). In contrast, the pathological workup showed a pCR (false positive CSR). The arrow indicates residual microcalcifications reaching the caudal margin
85 Patients $(48.9 \%)$ had a clinical complete response (cCR), whereas 89 (51.1\%) had no cCR. In 82 cases (47.1\%), NACT resulted in a pCR (ypT0).

\section{Histopathological margin infiltration by orientations}

The histopathological workup of the main specimen (without re-excisions), showed an infiltration of 47 (4.5\%) margins. The cranial and dorsal orientation most frequently showed margin involvement (14 positive margins, 1.3\%).

\section{Margin assessment by CSR}

In total, 1044 margins were analyzed with CSR (Table 2), of which 117 (11.2\%) were radiologically positive. Nine (0.9\%) were histologically and radiologically positive (true positive CSR). Based on the correct identification by CSR, these margins could be re-resected in the same surgery, potentially reaching a final negative margin state in the same surgery.

108 (10.3\%) histopathologically clear margins were falsely assessed as positive by CSR. In these cases, healthy tissue was re-resected unnecessarily if the surgeon followed the recommendation for re-excision.

Of 927 radiologically negative margins, 38 (4.1\%) were histologically infiltrated (false negative CSR). In these cases, no recommendation for re-excision was given based on CSR and the final margin status in the first surgery was positive (unless the surgeon performed a re-excision based on grossinspection), resulting in the necessity for a second surgery.

\section{Comparison of margin assessment between CCR and non-cCR patients}

Regarding all 1044 margins, CSR had a sensitivity of $19.2 \%$, specificity of $89.2 \%$, PPV of $7.7 \%$, and NPV of $95.9 \%$.

In the subgroup of $\mathrm{cCR}$ patients, the prevalence of histologically positive margins was 10 of 510 (2.0\%). One of these margins was correctly diagnosed as radiologically positive (true positive CSR, 10.0\%). In contrast, 51 of 500 histologically negative margins $(10.2 \%)$ were false positive in CSR.

Compared to the non-cCR patients, there was no relevant difference in specificity $(89.8 \%$ versus $88.5 \%, p=0.542)$. Sensitivity $(10.0 \%$ versus $21.6 \%, p=0.660)$ and PPV $(1.9 \%$ versus $12.3 \%, p=0.076$ ) were lower in the $\mathrm{cCR}$ subgroup, but the differences were not statistically significant.

\section{Intraoperative re-excisions and final positive margin status on case level}

In 95 (54.6\%) patients, at least one intraoperative re-excision was performed (Table 3$)$. In $79(83.2 \%)$ cases, this turned 
Table 1 Patient and tumor characteristics

\begin{tabular}{|c|c|}
\hline Number of patients & $(n=174)$ (percentages in brackets) \\
\hline \multicolumn{2}{|l|}{ Age } \\
\hline Mean & $51.4(12.2)$ \\
\hline Range & 24 to 82 \\
\hline Ethnicity & not systematically assessed, mostly European \\
\hline \multicolumn{2}{|l|}{ Cup size } \\
\hline A & $5(2.9)$ \\
\hline B & $46(26.4)$ \\
\hline $\mathrm{C}$ & $26(14.9)$ \\
\hline $\mathrm{D}$ & $14(8.0)$ \\
\hline $\mathrm{E}$ & $2(1.1)$ \\
\hline $\mathrm{F}$ & $1(0.6)$ \\
\hline Unknown & $80(45.4)$ \\
\hline \multicolumn{2}{|l|}{ Menopausal status } \\
\hline Premenopausal & $62(35.6)$ \\
\hline Menopausal & $22(12.6)$ \\
\hline Postmenopausal & $90(51.7)$ \\
\hline \multicolumn{2}{|l|}{ Breast density (ACR) } \\
\hline A & $11(6.3)$ \\
\hline $\mathrm{B}$ & $82(47.1)$ \\
\hline $\mathrm{C}$ & $61(35.1)$ \\
\hline $\mathrm{D}$ & $20(11.5)$ \\
\hline \multicolumn{2}{|l|}{ Target structure for lesion marking } \\
\hline Clip marker & $158(90.8)$ \\
\hline Clip marker detected in CSR & $154(97.4)$ \\
\hline Microcalcifications & $16(9.2)$ \\
\hline \multicolumn{2}{|c|}{ Radiographic presentation of the tumor } \\
\hline Only mass & 126 \\
\hline Mass with microcalcifications & 16 \\
\hline Only microcalcifications & 2 \\
\hline \multicolumn{2}{|l|}{ MRI performed } \\
\hline Before and after NACT & $18(10.3)$ \\
\hline Only before NACT & $68(39.1)$ \\
\hline Only after NACT & $5(2.8)$ \\
\hline \multicolumn{2}{|l|}{ Remission status } \\
\hline $\mathrm{cCR}$ & $85(48.9)$ \\
\hline With pCR (\%) & $58(68.2)$ \\
\hline Non-cCR & $89(51.1)$ \\
\hline With pCR (\%) & $25(28.1)$ \\
\hline \multicolumn{2}{|l|}{ Final T-stadium (ypT) } \\
\hline 0 & $82(47.1)$ \\
\hline is & $11(6.3)$ \\
\hline 1 & $62(35.6)$ \\
\hline$-1 \mathrm{mic}$ & $1(0.6)$ \\
\hline$-1 \mathrm{a}$ & $19(10.9)$ \\
\hline$-1 b$ & $14(8.0)$ \\
\hline$-1 c$ & $28(16.1)$ \\
\hline 2 & $17(9.8)$ \\
\hline 3 & $1(0.6)$ \\
\hline 4 & - \\
\hline \multicolumn{2}{|l|}{ Median specimen weight } \\
\hline Primary resection & $38.0 \mathrm{~g}$ (range $5 ; 268)$ \\
\hline
\end{tabular}


Table 1 (continued)

\begin{tabular}{ll}
\hline Number of patients & $(n=174)$ (percentages in brackets) \\
\hline Re-resection & $7.6 \mathrm{~g}$ (range 1; 41) \\
Histologically Infiltrated margins by orientation & \\
Total & $47(4.5)$ \\
Medial & $3(0.3)$ \\
Lateral & $3(0.3)$ \\
Kranial & $14(1.3)$ \\
Kaudal & $9(0.9)$ \\
Ventral & $4(0.4)$ \\
Dorsal & $14(1.3)$ \\
\hline
\end{tabular}

$c C R$ clinical complete response, $p C R$ pathological complete response

Table 2 Evaluation of Conventional Specimen Radiography on a margin level for the whole and for patients with clinical complete response versus no clinical complete response

\begin{tabular}{|c|c|c|c|c|c|c|c|}
\hline & \multicolumn{2}{|l|}{ Overall cohort } & \multicolumn{2}{|c|}{$\begin{array}{l}\text { Clinical complete response } \\
(\mathrm{cCR})\end{array}$} & \multicolumn{2}{|c|}{$\begin{array}{l}\text { No clinical complete response } \\
\text { (non-cCR) }\end{array}$} & \multirow{2}{*}{$\begin{array}{l}\text { Total-no. }(\%) \\
-\end{array}$} \\
\hline & CSR positive & CSR negative & CSR positive & CSR negative & CSR positive & CSR negative & \\
\hline Reference test positive* & 9 & 38 & 1 & 9 & 8 & 29 & - \\
\hline Reference test negative ${ }^{* *}$ & 108 & 889 & 51 & 449 & 57 & 440 & - \\
\hline \multirow[t]{2}{*}{ Total—no. $(\%)$} & $1044(100 \%)$ & & $510(100 \%)$ & & $534(100 \%)$ & & - \\
\hline & & $(95 \% \mathrm{CI})$ & & $(95 \% \mathrm{CI})$ & & $(95 \% \mathrm{CI})$ & $p$-value $* * *$ \\
\hline Sensitivity-\% (95\% CI) & $19.2 \%$ & $(9.2-33.3 \%)$ & $10.0 \%$ & $(0.3-44.5 \%)$ & $21.6 \%$ & $(9.8-38.2 \%)$ & 0.660 \\
\hline Specificity-\% (95\% CI) & $89.2 \%$ & $(87.1-91.0 \%)$ & $89.8 \%$ & $(86.8-92.3 \%)$ & $88.5 \%$ & $(85.4-91.2 \%)$ & 0.542 \\
\hline $\mathrm{PPV}-\%(95 \% \mathrm{CI})$ & $7.7 \%$ & $(3.6-14.1)$ & $1.9 \%$ & $(0.1-10.3 \%)$ & $12.3 \%$ & $(5.5-22.8 \%)$ & 0.076 \\
\hline NPV_—\% (95\% CI) & $95.9 \%$ & $(94.4-97.1 \%)$ & $98.0 \%$ & $(96.3-99.1 \%)$ & $93.8 \%$ & $(91.2-95.8)$ & 0.001 \\
\hline $\begin{array}{l}\text { Margin conversion } \\
\text { through CSR--no. }(\%)\end{array}$ & 15 & $(1.4 \%)$ & 1 & $(0.2 \%)$ & 14 & $(2.6 \%)$ & \\
\hline NNT & & 70 & & 510 & 38 & & \\
\hline
\end{tabular}

$c C R$ clinical complete response, CSR Conventional Specimen Radiography, NACT neoadjuvant chemotherapy, NNT number needed to treat, $N P V$ negative predictive value, $P M R$ positive margin rate, $P P V$ positive predictive value

*Tumor infiltrated margin in histopathologic evaluation of the surgical specimen

**No tumor infiltrated margin in histopathologic evaluation of the surgical specimen

***For clinical complete response versus no clinical complete response

out to be unnecessary, because all margins were histopathologically negative. In $16(9.2 \%)$ cases, margin infiltration was confirmed in histopathological examination. In 6 (3.4\%) cases, all histologically infiltrated margins were correctly identified by CSR. In the remaining $10(5.7 \%)$ cases, at least one histologically infiltrated margin was missed by CSR. Through intraoperative re-excisions, the number of infiltrated margins could be reduced from initially 47 (4.5\%) to $32(3.1 \%)$.

\section{Detection of clip markers by CSR}

154 of 158 (97.4\%) clip markers used for preoperative localization were detected in CSR. In three of the six remaining cases, the marker was preoperatively found to be dislocated (by $10 \mathrm{~mm}, 10 \mathrm{~mm}$, and $14 \mathrm{~mm}$, respectively) and was therefore not directly targeted with the wire marking. In one case, the clip marker was detected neither in CSR nor in a postsurgical control mammography (therefore, the clip must have been removed during the surgery without noticing by the surgeon), and in one case it was identified macroscopically by the surgeon and removed before CSR. In 16 cases, no clip marker had been applied because microcalcifications were used for wire localization of the target lesion.

\section{Effect of CSR-guided resections on secondary procedures}

In the whole cohort, 23 patients would have required further surgery if no margin assessment and no re-excisions had been carried out. Through intraoperative re-excisions based on CSR together with the gross assessment by the surgeon, 
Table 3 It shows the effect of CSR-guided re-resections on the final margin status and reduction of secondary surgeries on case level

\begin{tabular}{llll}
\hline & Overall cohort & cCR after NACT & Non-cCR after NACT \\
\hline Number of cases & $174(100 \%)$ & $85(100 \%)$ & $89(100 \%)$ \\
Initial PMR & $25(14.3 \%)$ & $7(8.2 \%)$ & $18(20.2 \%)$ \\
True positive & $13(7.5 \%)$ & $3(3.5 \%)$ & $10(11.2 \%)$ \\
False positive & $62(35.6 \%)$ & $33(38.8 \%)$ & $29(32.6 \%)$ \\
True negative & $87(50.0 \%)$ & $45(52.9 \%)$ & $42(47.2 \%)$ \\
False negative & $12(6.9 \%)$ & $4(4.7 \%)$ & $8(9.0 \%)$ \\
Sensitivity & $52.0 \%(31.3-72.2 \%)$ & $42.9 \%(9.9-81.6 \%)$ & $55.6 \%(30.8-78.5 \%)$ \\
Specificity & $58.4 \%(50.0-66.4 \%)$ & $57.7 \%(46.0-68.8 \%)$ & $59.2 \%(46.8-70.7 \%)$ \\
PPV & $17.3 \%(9.6-27.8 \%)$ & $8.3 \%(1.8-22.5 \%)$ & $25.6 \%(13.0-42.1 \%)$ \\
NPV & $87.9 \%(79.8-93.6 \%)$ & $91.8 \%(80.4-97.7 \%)$ & $84.0 \%(70.9-92.8 \%)$ \\
Final PMR & $17(9.8 \%)$ & $6(7.1 \%)$ & $11(12.4 \%)$ \\
Conversion of margin status through CSR & $8(4.6 \%)$ & $1(1.1 \%)$ & $7(7.9 \%)$ \\
NNT for conversion of margin status through CSR & 22 & 85 & 13 \\
Secondary surgeries & $16(9.2 \%)$ & $6(7.1 \%)$ & $10(11.2 \%)$ \\
Number of secondary surgeries avoided through CSR & $7(4 \%)$ & $1(1.1 \%)$ & $6(6.7 \%)$ \\
NNT to avoid secondary surgeries through CSR & 25 & 85 & 15 \\
\hline
\end{tabular}

$c C R$ clinical complete response, CSR Conventional Specimen Radiography, NACT neoadjuvant chemotherapy, NNT number needed to treat, $P M R$ positive margin rate in histology

clear margins were reached in 16 patients in the primary surgery. Thus, the rate of secondary procedures was reduced by $30.4 \%$, resulting in a NNT of 25 . In the cCR subgroup, the rate of secondary surgeries was reduced by $14.3 \%$ from seven to six patients by CSR-guided re-excisions. This translates to a NNT of 85 in the cCR subgroup.

\section{Comparison with the efficacy of CSR in a cohort of patients without NACT}

In Table 4, we compare the results to the previously published data from a cohort without NACT from the same breast unit. On the margin level, we found a similar specificity $(86.8 \%$, versus $89.8 \%, p=0.055)$, but a significantly lower sensitivity (19.2\%) in the NACT cohort compared to the non-NACT cohort $(36.8 \% ; p=0.012)$. The PPV is much lower after NACT than in the non-NACT cohort $(7.7 \%$ vs. $25.6 \% ; p=<0.001)$.

\section{Discussion}

There are numerous studies on the use of CSR, but comparability of the results is limited, mostly because the accuracy of CSR is not evaluated on a margin level [12, 18-21]. A meta-analysis by Versteegden et al. reported a large range of sensitivity from 22 to $77 \%$, specificity from 51 to $100 \%$, and PPV from 51 to $100 \%$, due to a large clinical and methodological diversity with low comparability of the studies [22]. While some studies [23-25], including a recent review by Gray et al. [26], indicate that CSR is not able to reduce the rate of positive margins and hence, the reoperation rate, Ciccarelli et al. and Chagpar et al. describe a reduction of the rate of second surgeries from 31 to $21 \%$ [12] and $37.8 \%$ to $28.9 \%$ [13].

The diagnostic accuracy of CSR in the present study including only patients after NACT was comparable to
Table 4 Analysis of CSR in Patients with and without NACT on margin level

\begin{tabular}{|c|c|c|c|c|c|}
\hline \multirow[b]{2}{*}{ Total margins } & \multicolumn{2}{|l|}{ No NACT ${ }^{a}$} & \multicolumn{2}{|l|}{ NACT } & \multirow[t]{2}{*}{$p$-value } \\
\hline & $(n=2826)$ & $(95 \% \mathrm{CI})$ & $(n=1044)$ & $(95 \% \mathrm{CI})$ & \\
\hline Infiltrated margins & $310(11.0 \%)$ & & $47(4.5 \%)$ & & \\
\hline Sensitivity & $36.8 \%$ & $(31.4-42.2 \%)$ & $19.1 \%$ & $(9.2-33.3 \%)$ & $0.012^{*}$ \\
\hline Specificity & $86.8 \%$ & $(85.5-88.1 \%)$ & $89.2 \%$ & $(87.1-91.0 \%)$ & $0.055^{*}$ \\
\hline Positive predictive value (PPV) & $25.6 \%$ & $(21.6-29.7 \%)$ & $7.7 \%$ & $(3.6-14.1 \%)$ & $<0.001^{*}$ \\
\hline Negative predictive value (NPV) & $91.8 \%$ & $(90.7-92.9 \%)$ & $95.9 \%$ & $(94.4-97.1 \%)$ & $<0.001 *$ \\
\hline
\end{tabular}

CI confidence interval, NACT neoadjuvant chemotherapy

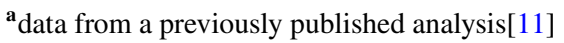


the results reported in the literature for non-selected cohorts, with sensitivity and specificity of $19.2 \%$ and $89.2 \%$, respectively. However, the prevalence of initially positive margins was low in the overall cohort $(n=47$, $4.5 \%)$ and even lower in the cCR cohort $(n=10,2.0 \%)$. Consequently, only a few patients could potentially benefit from intraoperative re-excisions led by CSR. Accordingly, the NNT were 25 in all NACT patients and 85 in the $\mathrm{cCR}$ subgroup. This means that 84 of 85 patients with a cCR would not benefit from CSR, while one second surgery could be avoided. Whether this is an acceptable rate, has to be discussed from a patient-based, clinical perspective. Listening to our patients' voice has gained more importance during the past years and should be considered as the tipping point in such controversial risk-benefit evaluations [28].

In cases with positive margin status, a secondary reexcision will be recommended to eliminate residual disease. Yet, some patients might decline a second surgery and thus do not achieve a finally negative margin. In this constellation, an intraoperative re-excision could have a relevant positive impact on oncologic safety.

Avoiding a second surgery also means a psychological advantage for the patients, and no second general anesthesia is needed. Lastly, esthetic outcome tends to be worse if two surgeries are necessary for definite treatment [29].

\section{False positives}

The false positive rate of all assessed margins was $10.3 \%$, which could lead to the unnecessary removal of healthy tissue if the recommendation for an intraoperative reexcision was followed. The impact of the re-excision on the esthetic outcome depends on the relation between the removed tissue and the breast size. [5, 30] The median specimen weight of the re-excisions in our study was $7.6 \mathrm{~g}$ (range $1 ; 41$ ). In patients with small breasts, even minimal re-excisions with unnecessary removal of tissue could have a relevant effect on the esthetic outcome.

One explanation for the high false positive rate might be that in unclear cases the radiologist might intuitively tend to report a positive than a negative margin for maximum oncologic safety. In addition, there is no consensus on which radiological margin width should result in a recommendation for re-excision.

The shrinkage of the surgical specimen upon resection described as "pancake phenomenon" by Graham et al. results in apparently smaller safety margins and can contribute to a false positive margin assessment. Inadequate compression of the specimen during CSR can also lead to a distortion of the tumor-margin-relation [31].
Finally, a large part of the lesion can be necrotic or fibrotic due tumor regression after NACT, which can falsely appear like residual tumor [32, 33, 36].

\section{Comparison of CCR versus non-cCR cases}

One would expect a very low prevalence of positive margins in patients with a $\mathrm{cCR}$, since many of these will have no residual tumor. In our analysis, we found only 10/510 (2.0\%) positive margins in the cCR cohort, compared to $37 / 534$ (6.9\%) in the non-cCR cases. As a result, the NNT of 85 to avoid one second surgery on case level is very high in the cCR group, versus 15 in the non-cCR group. In fact, when costs and risks of CSR-guided re-resections are balanced, CSR does not seem to be an appropriate tool for margin assessment in cCR patients. Apart from margin assessment, CSR is also used to test if the biopsy site clip was removed with the specimen as a real-time confirmation that surgery was performed in the correct localization of the tumor bed [27]. For this indication, CSR was very reliable in our analysis, since 154 or $97.4 \%$ of 158 clip markers were detected in CSR.

\section{Limitations}

Since this is a retrospective study, no change of clinical practice can be recommended based on the results. Although we assessed 1044 margins, the power of the statistical analysis is limited by the low prevalence of positive margins especially in the cCR subgroup.

One limitation in the study design is that re-excisions could be performed not only based on the recommendation of CSR but also on the subjective assessment of the surgeons (e.g., according to their clinical impression after gross inspection of the specimen and palpation of the operation site). In future studies, the surgeon should be asked to document systematically what influenced their decision to perform a re-excision (recommendation from CSR versus subjective decision).

According to the current clinical standard in our unit, CSR was performed as standard digital mammography. Some authors argue that using tomosynthesis for margin assessment retrieves better results with a higher sensitivity $[38,39]$. The potential benefit of tomosynthesis versus mammography is larger in patients with high breast density leading to a decreased diagnostic accuracy of CSR mammography.

An important source of error is the orientation and marking of the specimen. In the literature, rates of disorientation up to $31.1 \%$, are reported, particularly in small specimens [40]. At our clinic, there is clear instruction for a standardized marking of the specimen orientation, which should help 
to reduce the error rate. Still, depending on size, form, and texture of the specimen, a clear marking can be challenging.

Due to the low prevalence of positive margins in the whole cohort, we did not perform a subgroup analysis by tumor biology. However, tumor subtypes differ regarding the patterns of tumor regression, which leads to heterogeneous radiological appearances. It seems likely that this also influences the accuracy of CSR. In future studies with sufficient sample size for subgroup analyses, tumor biological subtypes should be considered.

\section{Conclusion}

The prevalence of initially positive margins after NACT and the sensitivity of CSR to detect them are low. A large proportion of patients might be overtreated by CSR-guided re-excisions. Balancing the benefit of a few spared second surgeries in relation to the much more frequent unnecessary or even harmful re-excisions after CSR, the use of CSR as a margin assessment tool cannot be generally recommended after NACT, particularly if a cCR was reached. Yet, CSR remains useful to document removal of the clip marker in the target lesion.

Authors' contributions Benedikt Schaefgen: Conceptualization, Methodology, Investigation, Writing-Original Draft. Annika Funk: Conceptualization, Methodology, Investigation, Writing-Review \& Editing. Peter Sinn: Investigation, Resources, Writing_-Review \& Editing. Thomas Bruckner: Formal analysis, Data Curation; Christina Gomez Andreu, Aba Harcos, Anne Stieber, Annabelle Haller, Juliane Nees, Riku Togawa, André Pfob, André Hennigs, Johanna Hederer, Fabian Riedel, Sarah Fastner: Investigation, Resources, Writing-review \& editing, Christof Sohn: Supervision; Resources; Joerg Heil: Investigation, Resources, Supervision, Writing-Review \& Editing; Michael Golatta: Conceptualization, Investigation, Resources, Writing-Review \& Editing, Project administration.

Funding Open Access funding enabled and organized by Projekt DEAL.

Data Availability Upon request from the corresponding author.

Code availability not applicable.

\section{Declarations}

Conflict of interest The authors declare that they have no conflict of interest related to this study.

Ethical approval This study was approved by the ethics committee of the University's Medical Faculty under file number S-468/2016.

Consent to participate Not applicable (retrospective analysis of anonymized data).
Consent for publication Given for all authors.

Open Access This article is licensed under a Creative Commons Attribution 4.0 International License, which permits use, sharing, adaptation, distribution and reproduction in any medium or format, as long as you give appropriate credit to the original author(s) and the source, provide a link to the Creative Commons licence, and indicate if changes were made. The images or other third party material in this article are included in the article's Creative Commons licence, unless indicated otherwise in a credit line to the material. If material is not included in the article's Creative Commons licence and your intended use is not permitted by statutory regulation or exceeds the permitted use, you will need to obtain permission directly from the copyright holder. To view a copy of this licence, visit http://creativecommons.org/licenses/by/4.0/.

\section{References}

1. Fisher B, Anderson S, Bryant J, Margolese RG, Deutsch M, Fisher ER, Jeong JH, Wolmark N (2002) Twenty-year follow-up of a randomized trial comparing total mastectomy, lumpectomy, and lumpectomy plus irradiation for the treatment of invasive breast cancer. N Engl J Med 347(16):1233-1241

2. Veronesi U, Cascinelli N, Mariani L, Greco M, Saccozzi R, Luini A, Aguilar M, Marubini E (2002) Twenty-year followup of a randomized study comparing breast-conserving surgery with radical mastectomy for early breast cancer. N Engl J Med 347(16):1227-1232

3. Hofvind S, Holen A, Aas T, Roman M, Sebuodegard S, Akslen LA (2015) Women treated with breast conserving surgery do better than those with mastectomy independent of detection mode, prognostic and predictive tumor characteristics. European J Surg Oncol 41(10): 1417-1422

4. Hwang ES, Lichtensztajn DY, Gomez SL, Fowble B, Clarke CA (2013) Survival after lumpectomy and mastectomy for early stage invasive breast cancer: the effect of age and hormone receptor status. Cancer 119(7):1402-1411

5. Hennigs A, Hartmann B, Rauch G, Golatta M, Tabatabai P, Domschke C, Schott S, Schutz F, Sohn C, Heil J (2015) Long-term objective esthetic outcome after breast-conserving therapy. Breast Cancer Res Treat 153(2):345-351

6. Foersterling E, Golatta M, Hennigs A, Schulz S, Rauch G, Schott S, Domschke C, Schuetz F, Sohn C, Heil J (2014) Predictors of early poor aesthetic outcome after breast-conserving surgery in patients with breast cancer: initial results of a prospective cohort study at a single institution. J Surg Oncol 110(7):801-806

7. Volders JH, Negenborn VL, Haloua MH, Krekel NMA, Jozwiak K, Meijer S, van den Tol PM (2018) Breast-specific factors determine cosmetic outcome and patient satisfaction after breast-conserving therapy: Results from the randomized COBALT study. J Surg Oncol 117(5):1001-1008

8. Heil J, Holl S, Golatta M, Rauch G, Rom J, Marme F, Gebauer G, Sohn C (2010) Aesthetic and functional results after breast conserving surgery as correlates of quality of life measured by a German version of the Breast Cancer Treatment Outcome Scale (BCTOS). Breast 19(6):470-474

9. Waljee JF, Hu ES, Ubel PA, Smith DM, Newman LA, Alderman AK (2008) Effect of esthetic outcome after breast-conserving surgery on psychosocial functioning and quality of life. J Clin Oncol 26(20):3331-3337

10. Horst KC, Smitt MC, Goffinet DR, Carlson RW (2005) Predictors of local recurrence after breast-conservation therapy. Clin Breast Cancer 5(6):425-438 
11. Funk A, Heil J, Harcos A, Gomez C, Stieber A, Junkermann H, Hennigs A, Rauch G, Sinn HP, Riedel F et al (2020) Efficacy of intraoperative specimen radiography as margin assessment tool in breast conserving surgery. Breast Cancer Res Treat 179(2):425-433

12. Ciccarelli G, Di Virgilio MR, Menna S, Garretti L, Ala A, Giani R, Bussone R, Canavese G, Berardengo E (2007) Radiography of the surgical specimen in early stage breast lesions: diagnostic reliability in the analysis of the resection margins. Radiol Med 112(3):366-376

13. Chagpar AB, Butler M, Killelea BK, Horowitz NR, Stavris K, Lannin DR (2015) Does three-dimensional intraoperative specimen imaging reduce the need for re-excision in breast cancer patients? A prospective cohort study. Am J Surg 210(5):886-890

14. von Minckwitz G, Untch M, Blohmer JU, Costa SD, Eidtmann H, Fasching PA, Gerber B, Eiermann W, Hilfrich J, Huober J et al (2012) Definition and impact of pathologic complete response on prognosis after neoadjuvant chemotherapy in various intrinsic breast cancer subtypes. J Clin Oncol 30(15):1796-1804

15. Heil J, Kuerer HM, Pfob A, Rauch G, Sinn HP, Golatta M, Liefers GJ, Vrancken Peeters MJ (2020) Eliminating the breast cancer surgery paradigm after neoadjuvant systemic therapy: current evidence and future challenges. Ann Oncol 31(1):61-71

16. Interdisziplinäre S3-Leitlinie für die Diagnostik, Therapie und Nachsorge des Mammakarzinoms [http://www.awmf.org/uploa ds/tx_szleitlinien/032-045OL_k_S3_Brustkrebs_Mammakarzi nom_Diagnostik_Therapie_Nachsorge_2012-07.pdf].

17. Fachgesellschaften AdWM: Interdisziplinäre S3-Leitlinie für die Früherkennung, Diagnostik, Therapie und Nachsorge des Mammakarzinoms. 2017.

18. McCormick JT, Keleher AJ, Tikhomirov VB, Budway RJ, Caushaj PF (2004) Analysis of the use of specimen mammography in breast conservation therapy. Am J Surg 188(4):433-436

19. Hisada T, Sawaki M, Ishiguro J, Adachi Y, Kotani H, Yoshimura A, Hattori M, Yatabe Y, Iwata H (2016) Impact of intraoperative specimen mammography on margins in breast-conserving surgery. Mol Clin Oncol 5(3):269-272

20. Schmachtenberg C, Engelken F, Fischer T, Bick U, Poellinger A, Fallenberg EM (2012) Intraoperative specimen radiography in patients with nonpalpable malignant breast lesions. Rofo 184(7):635-642

21. Mazouni C, Rouzier R, Balleyguier C, Sideris L, Rochard F, Delaloge S, Marsiglia H, Mathieu MC, Spielman M, Garbay JR (2006) Specimen radiography as predictor of resection margin status in non-palpable breast lesions. Clin Radiol 61(9):789-796

22. Versteegden DPA, Keizer LGG, Schlooz-Vries MS, Duijm LEM, Wauters CAP, Strobbe LJA (2017) Performance characteristics of specimen radiography for margin assessment for ductal carcinoma in situ: a systematic review. Breast Cancer Res Treat 166:669-679

23. Rua C, Lebas P, Michenet P, Ouldamer L (2012) Evaluation of lumpectomy surgical specimen radiographs in subclinical, in situ and invasive breast cancer, and factors predicting positive margins. Diagn Interv Imaging 93(11):871-877

24. Laws A, Brar MS, Bouchard-Fortier A, Leong B, Quan ML (2018) Does intra-operative margin assessment improve margin status and re-excision rates? A population-based analysis of outcomes in breast-conserving surgery for ductal carcinoma in situ. J Surg Oncol 118(7):1205-1211

25. Laws A, Brar MS, Bouchard-Fortier A, Leong B, Quan ML (2016) Intraoperative margin assessment in wire-localized breast-conserving surgery for invasive cancer: a population-level comparison of techniques. Ann Surg Oncol 23(10):3290-3296

26. Gray RJ, Pockaj BA, Garvey E, Blair S (2017) Intraoperative margin management in breast-conserving surgery: a systematic review of the literature. Ann Surg Oncol 25:18-27
27. Green RT, Weiser R, Golan O, Menes TS (2021) In search of the lost clip: outcome of women after needle-guided lumpectomy of a marking clip. Ann Surg Oncol 28(9):4974-4980

28. Heil J, Pfob A (2020) Patients should be the tipping point of individualizing breast cancer surgery: Commentary on "Eliminating the breast cancer surgery paradigm after neoadjuvant systemic therapy: current evidence and future challenges." Ann Oncol 31(9): 1264

29. Dahlback C, Manjer J, Rehn M, Ringberg A (2016) Determinants for patient satisfaction regarding aesthetic outcome and skin sensitivity after breast-conserving surgery. World J Surg Oncol 14(1):303

30. Cochrane RA, Valasiadou P, Wilson AR, Al-Ghazal SK, Macmillan RD (2003) Cosmesis and satisfaction after breast-conserving surgery correlates with the percentage of breast volume excised. Br J Surg 90(12):1505-1509

31. Clingan R, Griffin M, Phillips J, Coberly W, Jennings W (2003) Potential margin distortion in breast tissue by specimen mammography. Arch Surg 138(12):1371-1374

32. Helvie MA, Joynt LK, Cody RL, Pierce LJ, Adler DD, Merajver SD (1996) Locally advanced breast carcinoma: accuracy of mammography versus clinical examination in the prediction of residual disease after chemotherapy. Radiology 198(2):327-332

33. Moskovic EC, Mansi JL, King DM, Murch CR, Smith IE (1993) Mammography in the assessment of response to medical treatment of large primary breast cancer. Clin Radiol 47(5):339-344

34. Goorts B, van Nijnatten TJ, de Munck L, Moossdorff M, Heuts EM, de Boer M, Lobbes MB, Smidt ML (2017) Clinical tumor stage is the most important predictor of pathological complete response rate after neoadjuvant chemotherapy in breast cancer patients. Breast Cancer Res Treat 163(1):83-91

35. Kagihara JA, Andress M, Diamond JR (2020) Nab-paclitaxel and atezolizumab for the treatment of PD-L1-positive, metastatic triple-negative breast cancer: review and future directions. Expert Rev Precis Med Drug Dev 5(2):59-65

36. Schaefgen B, Mati M, Sinn HP, Golatta M, Stieber A, Rauch G, Hennigs A, Richter H, Domschke C, Schuetz F et al (2016) Can routine imaging after neoadjuvant chemotherapy in breast cancer predict pathologic complete response? Ann Surg Oncol 23(3):789-795

37. Pfob A, Sidey-Gibbons C, Lee HB, Tasoulis MK, Koelbel V, Golatta M, Rauch GM, Smith BD, Valero V, Han W et al (2021) Identification of breast cancer patients with pathologic complete response in the breast after neoadjuvant systemic treatment by an intelligent vacuum-assisted biopsy. Eur J Cancer 143:134-146

38. Amer HA, Schmitzberger F, Ingold-Heppner B, Kussmaul J, El Tohamy MF, Tantawy HI, Hamm B, Makowski M, Fallenberg EM (2017) Digital breast tomosynthesis versus full-field digital mammography-Which modality provides more accurate prediction of margin status in specimen radiography? Eur J Radiol 93:258-264

39. Park KU, Kuerer HM, Rauch GM, Leung JWT, Sahin AA, Wei W, Li Y, Black DM (2019) Digital breast tomosynthesis for intraoperative margin assessment during breast-conserving surgery. Ann Surg Oncol 26(6):1720-1728

40. Molina MA, Snell S, Franceschi D, Jorda M, Gomez C, Moffat FL, Powell J, Avisar E (2009) Breast specimen orientation. Ann Surg Oncol 16(2):285-288

Publisher's Note Springer Nature remains neutral with regard to jurisdictional claims in published maps and institutional affiliations. 


\section{Authors and Affiliations}

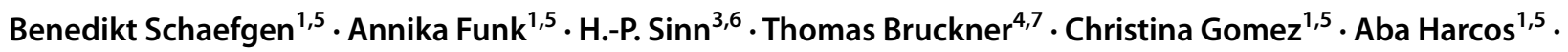
Anne Stieber ${ }^{2,8}$. Annabelle Haller ${ }^{1,5}$. Juliane Nees ${ }^{1,5} \cdot$ Riku Togawa $^{1,5}$. André Pfob ${ }^{1,5}$. André Hennigs ${ }^{1,5}$. Johanna Hederer $^{1,5} \cdot$ Fabian Riedel $^{1,5} \cdot$ Sarah Fastner ${ }^{1,5} \cdot$ Christof Sohn $^{1,5} \cdot$ Jörg Heil ${ }^{1,5} \cdot$ Michael Golatta $^{1,5}$ (D)

Benedikt Schaefgen

benedikt.schaefgen@med.uni-heidelberg.de

Annika Funk

annikaf91@gmail.com

H.-P. Sinn

peter.sinn@med.uni-heidelberg.de

Thomas Bruckner

bruckner@imbi.uni-heidelberg.de

Christina Gomez

christina.gomezandreu@med.uni-heidelberg.de

Aba Harcos

aba.harcos@med.uni-heidelberg.de

Anne Stieber

anne.stieber@med.uni-heidelberg.de

Annabelle Haller

annabelle.haller1@gmail.com

Juliane Nees

juliane.nees@med.uni-heidelberg.de

Riku Togawa

riku.togawa@med.uni-heidelberg.de

André Pfob

andre.pfob@med.uni-heidelberg.de

André Hennigs

andre.hennigs@med.uni-heidelberg.de

Johanna Hederer

johanna.hederer@web.de
Fabian Riedel

fabian.riedel@med.uni-heidelberg.de

Sarah Fastner

sarah.fastner@med.uni-heidelberg.de

Christof Sohn

christof.sohn@med.uni-heidelberg.de

Jörg Heil

joerg.heil@med.uni-heidelberg.de

1 Department of Gynecology and Obstetrics, University of Heidelberg, Heidelberg, Germany

2 Department of Radiology, University of Heidelberg, Heidelberg, Germany

3 Department of Pathology, University of Heidelberg, Heidelberg, Germany

4 IMBI- Institute for Medical Biometry and Informatics University of Heidelberg, Heidelberg, Germany

5 Universitätsfrauenklinik, INF 440, 69120 Heidelberg, Germany

6 Pathologisches Institut, INF 224, 69120 Heidelberg, Germany

7 IMBI, INF 130.3, 69120 Heidelberg, Germany

8 Klinik Für Radiologie, INF 110, 69120 Heidelberg, Germany 